\title{
Numerical application to monitor diffusion pressure on the deposition of fungi in slight heterogeneous phreatic deposition
}

\begin{abstract}
These paper monitors the behaviour of fungi in slight heterogeneous phreatic bed, the study express the rate of pressure from diffusion on fungi deposition in the study environment, the refection of predominant deposition of diffusion were observed from the graphical representation. The simulation values generated the following results that ranged from $0.0024-0.0918,1.0342-1.1842,0.9054-0.0945,1.087-0.02195$, $0.0068-0.035$, the study express the fluctuation base on the influence from this variables, the study area where there is fluctuation implies that diffusion deposition fluctuate in those strata, the reflection from this pressure were still insignificant as the concentration could not meet the required standard for quality groundwater to be consumed by human.
\end{abstract}

Keywords: numerical, diffusion fungi heterogeneous, phreatic bed, numerical modeling, concentration
Volume 2 Issue I - 2018

\author{
Eluozo SN,Afiibor BB,Amagbo LG \\ Department of Civil Engineering, Gregory University Uturu, \\ Nigeria
}

\begin{abstract}
Correspondence: Eluozo SN, Department of Civil Engineering, Gregory University Uturu (GUU)
\end{abstract}

Abia State of Nigeria, Email Soloeluozo20I3@hotmail.com

Received: June 28, 2017 | Published: January 29, 2018

\section{Introduction}

The cost of drinking water treatment and the taste and odor problems have increased significantly in the past decade. While nitrogen is a concern, phosphorous $(\mathrm{P})$ is generally considered the most limiting nutrient. The majority of $\mathrm{P}$ loading to the lake in this area comes from surface-applied poultry litter. Of the $48,000 \mathrm{~kg} / \mathrm{yr}$ of phosphorous entering Lake Eucha, $69 \%$ is thought to come from poultry litter application as fertilizer to pasture and crops in the cost of drinking water treatment and the taste and odor problems have increased significantly in the past decade. While nitrogen is a concern, phosphorous $(\mathrm{P})$ is generally considered the most limiting nutrient. The majority of $\mathrm{P}$ loading to the lake in this area comes from surfaceapplied poultry litter. Of the $48,000 \mathrm{~kg} / \mathrm{yr}$ of phosphorous entering Lake Eucha, $69 \%$ is thought to come from poultry litter application as fertilizer to pasture and crops in Excessive soil $\mathrm{P}$ concentrations can increase potential $\mathrm{P}$ transport to surface waters or leaching into the subsurface. This can have serious negative implications. Daniel et al. (1998) found that concentrations of P critical for terrestrial plant growth were an order of magnitude larger than concentrations at which lake eutrophication may occur Subsurface $\mathrm{P}$ transport is a less studied and understood transport mechanism compared to transport by overland flow, although abundant studies have reported its occurrence. ${ }^{1-5}$ For example, Andersen and Krovang (2006) modified a P Index to integrate potential $\mathrm{P}$ transport pathways of tile drains and leaching in Denmark. Hively et al. ${ }^{2}$ considered transport of total dissolved P (TDP) for both base flow and surface runoff. Nelson et al. ${ }^{5}$ indicated that phosphorus leaching and subsurface transport should be considered when assessing long-term risk of $\mathrm{P}$ loss from waste amended soils. Kleinman et $\mathrm{al}^{4}{ }^{4}$ noted that the P leaching is a significant, but temporally and spatially variable transport pathway. From research on four grassland soils, Turner \& Hunt et al. ${ }^{6}$ documented that subsurface $\mathrm{P}$ transfer, primarily in the dissolved form, can occur at concentrations that could cause eutrophication. Other researchers are beginning to emphasize colloidal P transport in the subsurface, as $\mathrm{P}$ attaches to small size particles capable of being transported through the soil pore spaces..$^{7-10}$ The Millennium Declaration in 2000 and the subsequent formulation of targets under the Millennium Development Goals (MDGs) marked a fundamental change. As the official monitoring instrument for progress towards achieving MDG 7 target C, the JMP prepares biennial global updates of this progress. Prior to 2000, JMP assessments had been undertaken in 1991, 1993, 1996 and 2000. The results for the year 2000 survey are presented in Global water supply and sanitation assessment 2000 report (WHO/UNICEF, 2000), which contains data for six global regions: Africa, Asia, Europe, Latin America and the Caribbean, Northern America, and Oceania. This report introduced a monitoring approach based on household surveys and censuses which has subsequently been refined. The methods and procedures lead to an estimate of numbers of people with access to improved water sources and improved sanitation. The Millennium Declaration in 2000 and the subsequent formulation of targets under the Millennium Development Goals (MDGs) marked a fundamental change. As the official monitoring instrument for progress towards achieving MDG 7 target C, the JMP prepares biennial global updates of this progress. Prior to 2000, JMP assessments had been undertaken in 1991, 1993, 1996 and 2000. The results for the year 2000 survey are presented in Global water supply and sanitation assessment 2000 report (WHO/ UNICEF, 2000), which contains data for six global regions: Africa, Asia, Europe, Latin America and the Caribbean, Northern America, and Oceania. This report introduced a monitoring approach based on household surveys and censuses which has subsequently been refined. The methods and procedures lead to an estimate of numbers of people with access to improved water sources and improved sanitation. If the current trend continues, the MDG drinking-water target will be exceeded by 2015 , but the sanitation target will be missed by about 1 billion people (over and above the 1.7 billion who would not have access even if the target were achieved). In the past, the JMP drew guidance from a technical advisory. 


\section{Governing equation}

The Implicit Scheme Numerical Solution

$$
\frac{\partial C}{\partial t}=\frac{Q}{A} \frac{\partial C}{\partial x}+D \frac{\partial^{2} C}{\partial x^{2}}+\frac{q L_{I N}}{A} C
$$

But $\frac{Q}{A}=$ Velocity, v in meter per second $(\mathrm{m} / \mathrm{s})$.

Thus equation (1) becomes:

$$
\frac{\partial C}{\partial t}=v \frac{\partial C}{\partial x}+D \frac{\partial^{2} C}{\partial x^{2}}+\frac{q L_{I N}}{A} C
$$

Converting the PDE to its algebraic equivalent equation by applying the finite different approximation technique for the implicit scheme, we obtain as follows.

$$
\begin{aligned}
& \frac{\partial C}{\partial t}=\frac{C_{i}^{j+1}-C_{i}^{j}}{\Delta t} \\
& \frac{\partial C}{\partial x}=\frac{C_{i+1}^{j+1}-C_{i-1}^{j+1}}{2 \Delta x} \\
& \frac{\partial^{2} C}{\partial x^{2}}=\frac{C_{i+1}^{j+1}-2 C_{i}^{j+1}+C_{i-1}^{j+1}}{\Delta x^{2}}
\end{aligned}
$$

Substituting equation (3) through (5) into (2) gives:

$$
\begin{gathered}
\frac{C_{i}^{j=1}-C_{i}^{j}}{\Delta t}=v\left[\frac{C_{i+1}^{j+1}-C_{i-1}^{j+1}}{2 \Delta x}\right]+D\left[\frac{C_{i+1}^{j+1}-2 C_{i}^{j+1}+C_{i-1}^{j+1}}{\Delta x^{2}}\right]+\frac{q L_{I N}}{A} C_{i}^{j+1} \\
C_{i}^{j+1}-C_{i}^{j}=\frac{\Delta t}{2 \Delta x} v\left[C_{i+1}^{j+1}-C_{i-1}^{j+1}\right]+\frac{\Delta t D}{\Delta x^{2}}\left[C_{i+1}^{j+1}-2 C_{i}^{j+1}+C_{i-1}^{j+1}\right]+\frac{\Delta t q L_{I N}}{A} C_{l}^{j+1} \\
C_{i}^{j+1}-C_{i}^{j}=\lambda\left(C_{i+1}^{j+1}-C_{i-1}^{j+1}\right)+K\left(C_{i+1}^{j+1}-2 C_{i}^{j+1}+C_{i-1}^{j+1}\right)+\alpha C_{i}^{j+1} \\
\text { Or } \\
C_{i}^{j}+(\alpha-\lambda-2 K-1) C_{i}^{j+1}+(\lambda+K) C_{i+1}^{j+1}+K C_{i-1}^{j+1}=0
\end{gathered}
$$

For cases where the initial and final conditions are given, boundary condition at the first node can be expressed as:

$$
C_{0}^{j+1}=f_{0}\left(t^{j+1}\right)
$$

Hence, first node equation is expressed as:

$$
C_{i}^{j}+(\alpha-\lambda-2 K-1) C_{i}^{j+1}+(\lambda+K) C_{i+1}^{j+1}=-K f_{0}\left(t^{j+1}\right)
$$

Similarly, the last node boundary condition is:

$$
\begin{aligned}
& C_{l}^{j+1}=f_{l+1}\left(t^{j+1}\right) \\
& C_{l}^{j}+(\alpha-\lambda-2 K-1) C_{l}^{j+1}+K C_{l-1}^{j+1}=-(\lambda+K) f_{l+1}\left(t^{j+1}\right)
\end{aligned}
$$

For $1 \leq x \leq 9$ and $0 \leq t \leq 4$; and for the first instance, we obtain as follows:

At time $=0($ i.e $j=0)$ :

$i=1$,

$$
\begin{aligned}
& C_{1}^{0}+K C_{0}^{1}+(\alpha-\lambda-2 K-1) C_{1}^{1}+(\lambda+K) C_{2}^{1}=0 \\
& C_{1}^{0}+(\alpha-\lambda-2 K-1) C_{1}^{1}+(\lambda+K) C_{2}^{1}=-K f_{0}\left(t^{1}\right) \\
& i=2,
\end{aligned}
$$$$
C_{2}^{0}+K C_{1}^{1}+(\alpha-\lambda-2 K-1) C_{2}^{1}+(\lambda+K) C_{3}^{1}=0
$$$$
i=3 \text {, }
$$$$
C_{3}^{0}+K C_{2}^{1}+(\alpha-\lambda-2 K-1) C_{3}^{1}+(\lambda+K) C_{4}^{1}=0
$$$$
i=4 \text {, }
$$$$
C_{4}^{0}+K C_{3}^{1}+(\alpha-\lambda-2 K-1) C_{4}^{1}+(\lambda+K) C_{5}^{1}=0
$$

$i=5$,

$C_{5}^{0}+K C_{4}^{1}+(\alpha-\lambda-2 K-1) C_{5}^{1}+(\lambda+K) C_{6}^{1}=0$

$i=6$,

$C_{6}^{0}+K C_{5}^{1}+(\alpha-\lambda-2 K-1) C_{6}^{1}+(\lambda+K) C_{7}^{1}=0$

$i=7$,

$C_{7}^{0}+K C_{6}^{1}+(\alpha-\lambda-2 K-1) C_{7}^{1}+(\lambda+K) C_{8}^{1}=0$

$i=8$,

$C_{8}^{0}+K C_{7}^{1}+(\alpha-\lambda-2 K-1) C_{8}^{1}+(\lambda+K) C_{9}^{1}=0$

$i=9$,

$C_{9}^{0}+K C_{8}^{1}+(\alpha-\lambda-2 K-1) C_{9}^{1}=-(\lambda+K) f_{10}\left(t^{1}\right)$

Atime, $t=0, C_{1}^{0}=C_{2}^{0}=C_{3}^{0}=C_{4}^{0}=C_{5}^{0}=C_{6}^{0}=C_{7}^{0}=C_{8}^{0}=C_{9}^{0}=0$ Arranging equations (6a) through (6i) in vector matrix gives:

$\left[\begin{array}{ccccccccc}\omega & \lambda+K & 0 & 0 & 0 & 0 & 0 & 0 & 0 \\ K & \omega & \lambda+K & 0 & 0 & 0 & 0 & 0 & 0 \\ 0 & K & \omega & \lambda+K & 0 & 0 & 0 & 0 & 0 \\ 0 & 0 & K & \omega & \lambda+K & 0 & 0 & 0 & 0 \\ 0 & 0 & 0 & K & \omega & \lambda+K & 0 & 0 & 0 \\ 0 & 0 & 0 & 0 & K & \omega & \lambda+K & 0 & 0 \\ 0 & 0 & 0 & 0 & 0 & K & \omega & \lambda+K & 0 \\ 0 & 0 & 0 & 0 & 0 & 0 & K & \omega & \lambda+K \\ 0 & 0 & 0 & 0 & 0 & 0 & 0 & K & \omega\end{array}\right]\left\{\begin{array}{c}C_{1}^{1} \\ C_{2}^{1} \\ C_{3}^{1} \\ C_{4}^{1} \\ C_{5}^{1} \\ C_{6}^{1} \\ C_{7}^{1} \\ C_{8}^{1} \\ C_{9}^{1}\end{array}\right\}=\left\{\begin{array}{c}-K f_{0}\left(t^{1}\right) \\ 0 \\ 0 \\ 0 \\ 0 \\ 0 \\ 0 \\ 0 \\ -(\lambda+K) f_{10}\left(t^{1}\right)\end{array}\right\}$

Where:

$\omega=(\alpha-\lambda-2 K-1)$

Hence, at any point with time, the general form of the above equation is presented as: 


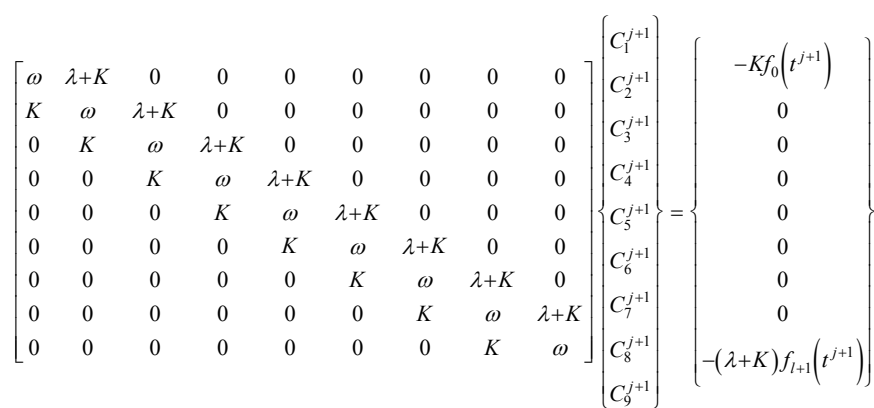

\section{Method of application}

numerical Method were applied through the developed system to generate the governing equations, derived solution generated the derived model solution, this were simulated to monitor the contaminants at different depth, values of contaminant known as concentration at different depth were generated, this results are within the values of concentration from other experimental values from the same contaminant by other experts, validation of the developed model is a thorough concept for monitoring such microbes in deltaic environment.

\section{Results and discussion}

Results and discussion are presented in tables including graphical representation for Fungi stated below.

The study show the of fungi deposition and its growth rate between the intercedes of the formation, the contaminant rapidly increase to the optimum rate recorded at $20 \mathrm{~m}$, sudden decrease was experienced between 25-30m. (Figure 1) (Figure 2) developed exponential phase of migration with slight fluctuation in where the optimum rate are recorded at $30 \mathrm{~m}$, while Figure 3 experiences sudden increase where the optimum are observed at $10 \mathrm{~m}$, sudden decrease were experienced to the lowest rate of concentration recorded at $30 \mathrm{~m}$. Figure 4 experiences similar condition, maximum concentration was experienced at five metres, while sudden degradation was observed in gradual process to the lowest rate recorded at $30 \mathrm{~m}$. Figure 5 maintained exponential phase were the growth rate increase with respect to change in depth to the optimum level recorded at $30 \mathrm{~m}$ (Tables 1-5).

Table I Simulation Values from Fungi Concentration at Different Depth

\begin{tabular}{ll}
\hline Depth $(\mathrm{m})$ & Concentration $(\mathrm{g} / \mathrm{ml})$ \\
\hline 0 & 0.0024 \\
3 & 0.0257 \\
6 & 0.0477 \\
9 & 0.0677 \\
12 & 0.085 \\
15 & 0.0988 \\
18 & 0.1085 \\
21 & 0.1133 \\
24 & 0.1126 \\
27 & 0.1057 \\
30 & 0.0918 \\
\hline
\end{tabular}

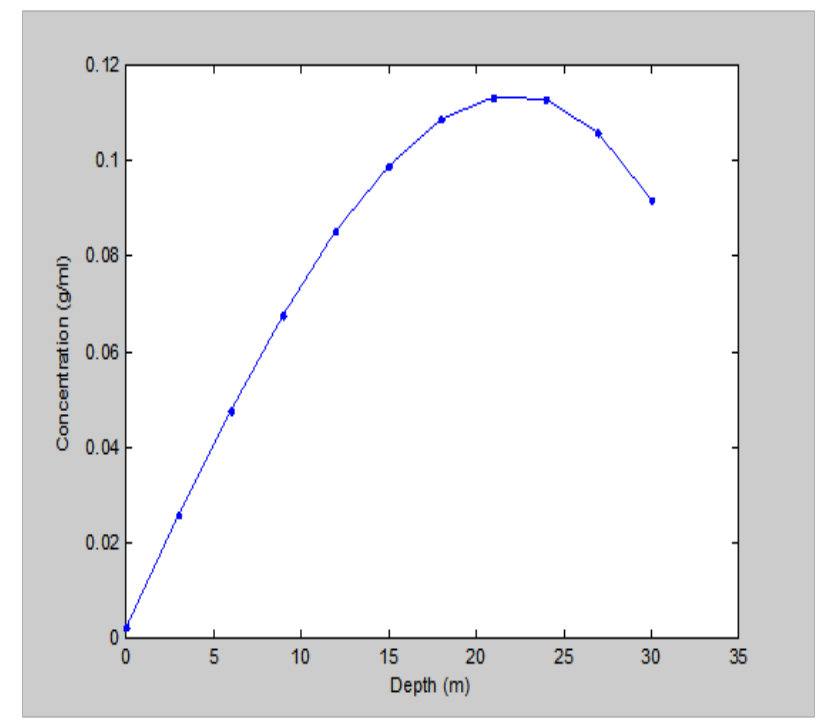

Figure I Simulation Values from Fungi Concentration at Different Depth.

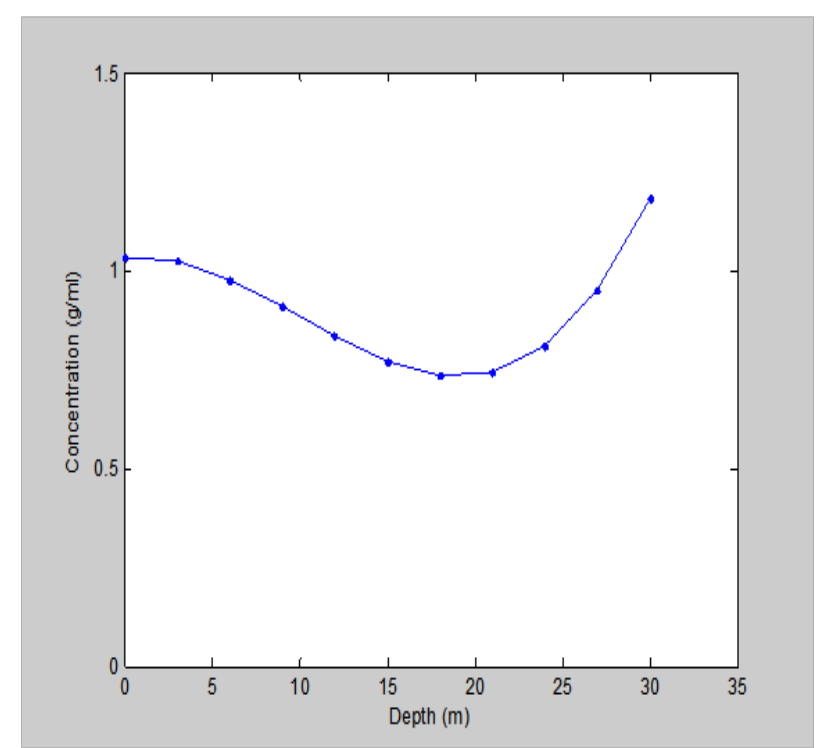

Figure 2 Simulation Values from Fungi Concentration at Different Depth.

Table 2 Simulation Values from Fungi Concentration at Different Depth

\begin{tabular}{ll}
\hline Depth(m) & Concentration(g/L) \\
\hline 0 & 1.0342 \\
3 & 1.0249 \\
6 & 0.9778 \\
9 & 0.9091 \\
12 & 0.835 \\
15 & 0.7717 \\
18 & 0.7354 \\
21 & 0.7423 \\
24 & 0.8086 \\
27 & 0.9505 \\
30 & 1.1842 \\
\hline
\end{tabular}




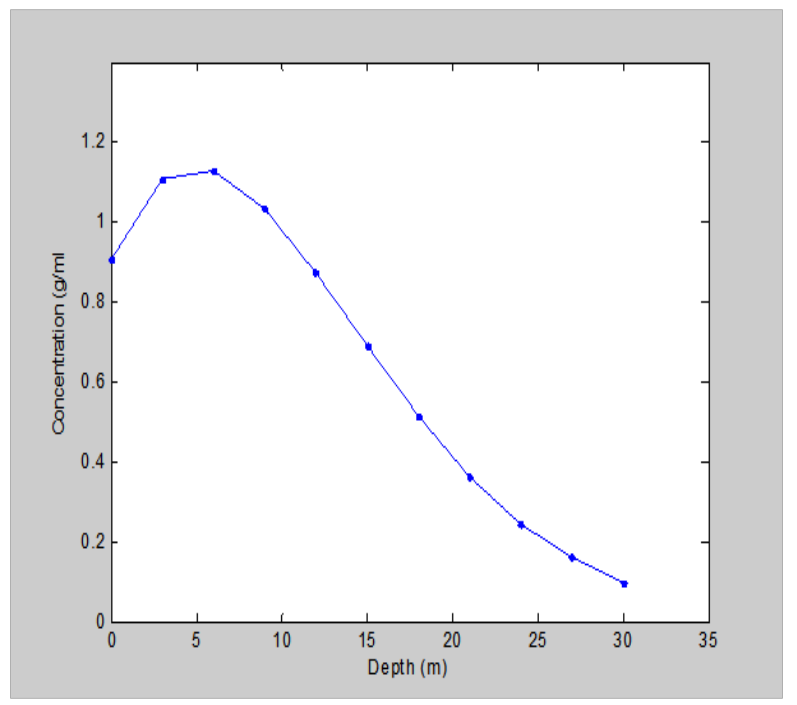

Figure 3 Simulation Values from Fungi Concentration at Different Depth.

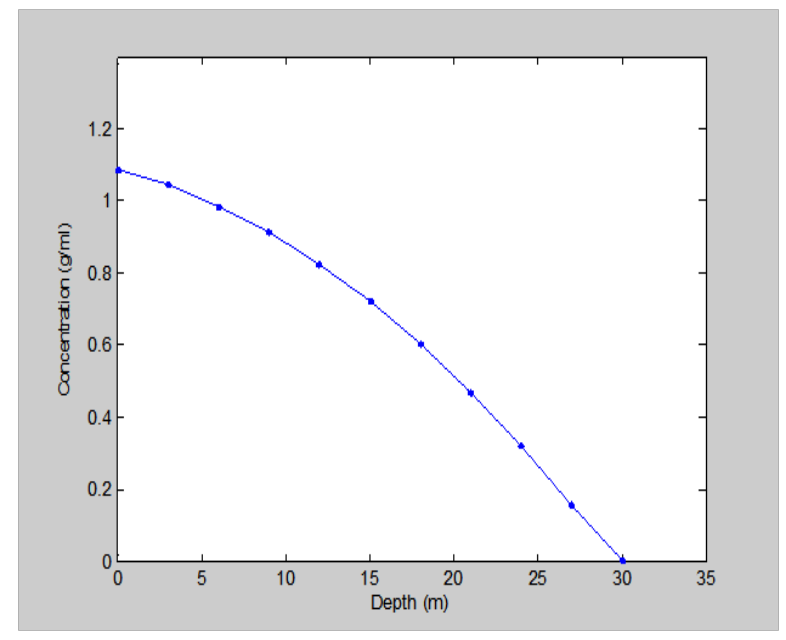

Figure 4 Simulation Values from Fungi Concentration at Different Depth. Table 3 Simulation Values from Fungi Concentration at Different Depth

\begin{tabular}{ll} 
Depth(m) & Concentration(g/L) \\
\hline 0 & 0.9054 \\
3 & 1.106798 \\
6 & 1.128391 \\
9 & 1.033118 \\
12 & 0.873029 \\
15 & 0.689288 \\
18 & 0.512172 \\
21 & 0.361074 \\
24 & 0.244498 \\
27 & 0.160062 \\
30 & 0.0945 \\
\hline
\end{tabular}

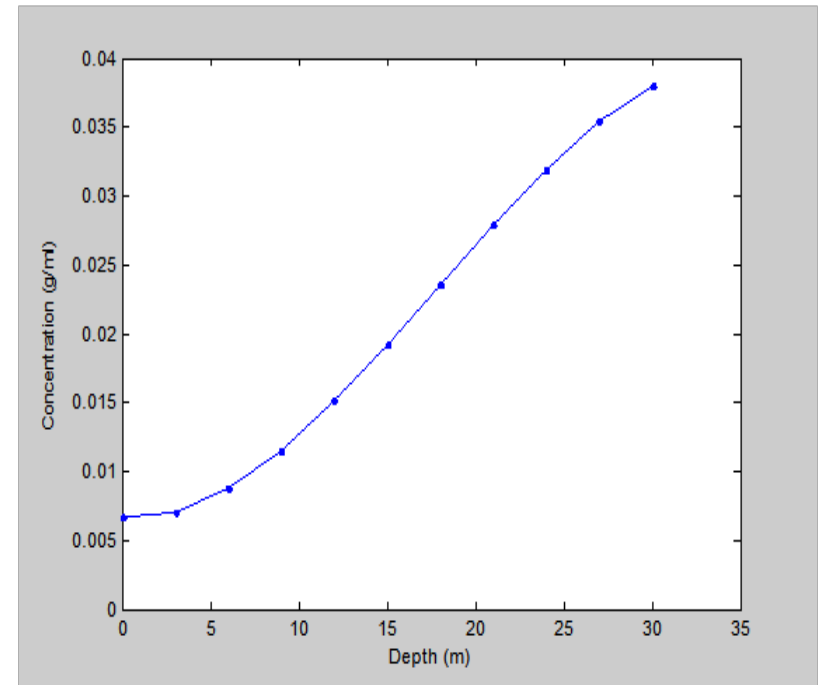

Figure 5 Simulation Values from Fungi Concentration at Different Depth.

Table 4 Simulation Values from Fungi Concentration at Different Depth

\begin{tabular}{ll}
\hline Depth(m) & Concentration(g/L) \\
\hline 0 & 1.087 \\
3 & 1.044267 \\
6 & 0.986386 \\
9 & 0.913359 \\
12 & 0.825184 \\
15 & 0.721863 \\
18 & 0.603394 \\
21 & 0.469779 \\
24 & 0.321016 \\
27 & 0.157107 \\
30 & 0.002195 \\
\hline
\end{tabular}

Table 5 Simulation Values from Fungi Concentration at Different Depth

\begin{tabular}{ll}
\hline Depth $(\mathbf{m})$ & Concentration $(\mathrm{g} / \mathrm{L})$ \\
\hline 0 & 0.0068 \\
3 & 0.0071 \\
6 & 0.0088 \\
9 & 0.0116 \\
12 & 0.0151 \\
15 & 0.0192 \\
18 & 0.0236 \\
21 & 0.0279 \\
24 & 0.0319 \\
27 & 0.0353 \\
30 & 0.0379 \\
\hline
\end{tabular}




\section{Conclusion}

The study examine the deposition rate of fungi under the influences of predominant diffusion between intercedes of the formation. The depositions of diffusion between the strata express predominant pressure in the migration of fungi in study environment, the heterogeneity in there depositions were also observed to affect the rate of migration, the study experienced fluctuation base on the pressure of predominant diffusion, slight heterogeneous in phreatic bed was found significant on the pressure of the transport system, the study has thoroughly detail the behavior of fungi deposition on an environment where there is significant diffusion in the formation, these condition were observed in the graphical representation of the concentration, it has definitely express the effect from diffusion on the transport process of fungi in slight heterogeneous environment

\section{Acknowledgments}

None.

\section{Conflicts of interest}

Author declares that there is no conflict of interest.

\section{References}

1. Heathwaite L, Haygarth P, Matthews R, et al. Evaluating colloidal phosphorus delivery to surface waters from diffuse agricultural sources. Journal of Environmental Quality. 2005;34(1):287-298.

2. Hively WD, Gerard-Marchant P, Steenhuis TS. Distributed hydrological modeling of total dissolved phosphorus transport in an agricultural landscape II. Dissolved phosphorus transport. Hydrology and Earth System Sciences. 2006;10(2):263-276.
3. Ilg K, Kaupenjohann M. Colloidal and dissolved phosphorus in sandy soils as affected by phosphorus saturation. $J$ Environ Qual. 2005;34(3):926-935.

4. Kleinman PJA, Needelman BA, Sharpley AN, et al. Using soil phosphorus profile data to assess phosphorus leaching potential in manured soils. Soil Science Society of America Journal. 2004;67(1):215-224.

5. Nelson NO, Parsons JE, Mikkelson RL. Field-scale evaluation of phosphorus leaching in acid sandy soils receiving swine waste. Journal of Environmental Quality. 2005;34(6):2024-2035.

6. Hunt B. Dispersive sources in uniform ground-water flow. American Society of Civil Engineering Journal Hydraulics Division. 1978;104(1):75-85.

7. Wagner K, Woodruff S. Phase I Clean Lakes Project, Diagnostic and Feasibility Study of Lake Eucha. Oklahoma Conservation Commission, USA; 1997.

8. Storm DE, White MJ, Smolen MD, et al. Modeling Phosphorus Loading for the Lake Eucha Basin. USA; 2001.

9. Storm DE, White MJ, Smolen MD. Modeling the Lake Eucha Basin Using SWAT 2000. Oklahoma State University, USA; 2002.

10. John WF. Subsurface transport of phosphorus in riparian loodplains: tracer and phosphorus transport experiments. University of Mississippi Oxford, USA; 2006. 